\title{
The temperature effect on portland cement strength
}

\author{
Yurii Abzaev ${ }^{1, *}$, Aleksei Gnyrya ${ }^{1}$, Sergei Korobkov ${ }^{1}$, Danil Dudov ${ }^{1}$, Dmitrii Mihailov ${ }^{1}$, and \\ Bogdan Vodnev ${ }^{1}$ \\ ${ }^{1}$ Tomsk State University of Architecture and Building, 2, Solyanaya Sq., 634003, Tomsk, Russia
}

\begin{abstract}
The paper presents the results of predictive modelling of the curing mechanism of the type CEM I 42.5B Portland cement using the VCCTL tool. The cement curing is studied during 28 days within the 0-99 ${ }^{\circ} \mathrm{C}$ temperature range. It is shown that the degree of Portland cement hydration is $\sim 0.55$ at $10{ }^{\circ} \mathrm{C}$, and with the temperature increase the hydration process substantially intensifies. The hydration degree of 0.75 is achieved after 50 hours at a temperature over $90{ }^{\circ} \mathrm{C}$. The VCCTL modelling is used to determine the quantitative content of the initial minerals and the main reaction products calcium silicate hydrate comprising C-S-H and portlandite $(\mathrm{CH})$. Their total amount significantly grows during the indicated time period. In Portland cement, the amount of clinker minerals decreases, whereas the fraction of hydrated cement comprising C-S-H and $\mathrm{CH}$ achieves 0.70 of the solid phase and pore space. The temperature has a great effect on these processes. The pore space reduces with the increasing time and temperature. It is found that the effective elastic moduli of Portland cement rapidly grow during 400 hours and achieve the following values: $16.79 \mathrm{MPa}$ for the bulk modulus, 8.90 MPa for the shear modulus and 22.69 MPa for Young's modulus. The equivalence of the VCCTL modelling of cement curing is examined by a search for the correlation between the experimental values of the yield stress at 20,40,50 and $70{ }^{\circ} \mathrm{C}$ and Young's modulus. With a high degree of reliability, this correlation matches the cubic function which is in agreement with the literature data.
\end{abstract}

\section{Introduction}

The laboratory tests of concrete products are rather expensive and labour-intensive. The model-based testing of physicochemical properties of concretes after 28-day curing allows a user to significantly reduce the time, materials, and human resources. Portland cement curing is a complex process which includes many mechanisms, each of which is described by its own group of variables. A consistent description of Portland cement curing requires the quantitative data on the initial phase composition, water-cement ratio, activation energy of the dissolution of clinker phases, heat generation in forming the intermediate and final products, porosity, bound moisture,

\footnotetext{
* Corresponding author: abzaev2010@yandex.ru
} 
ion composition (electrical conductivity) of aqueous solution, humidity, external conditions, composition, amount, and elastic properties of hydration products. The experimental study of these properties using the group of variables describing curing of Portland cement as a hierarchical system is rather difficult and requires the process modelling. One of the most efficient tools of the predictive modelling of cement properties is the Virtual Cement and Concrete Testing Laboratory (VCCTL) [1-5].

The aim of this work is to explore the curing mechanisms of the type CEM I 42.5B Portland cement using the VCCTL computer modelling tool. This cement type is similar to that manufactured at the Topki Cement Plant (the Novosibirsk region, Russia). Investigations are carried out during 28 days of curing within the $0-99{ }^{\circ} \mathrm{C}$ temperature range and 0.40 water-cement ratio.

\section{Materials and methods}

The type CEM I 42.5B Portland cement was investigated in this experiment. This type of Portland cement was used a binder in manufacturing heavy concretes possessing high performance properties. Its chemical composition allowed us to perform the Bogue calculations [6]. In $100 \mathrm{~g}$ of Portland cement $61.06 \mathrm{~g}$ alite, $13.62 \mathrm{~g}$ belite, 12.79 $\mathrm{g}$ ferrite and $6.50 \mathrm{~g}$ aluminate were found. Table 1 presents the chemical composition and weight content of CEM I 42.5B, including $40 \mathrm{~g}$ water and $0.34 \mathrm{~g}$ oxygen content which was used for hydration modelling. The water-cement ratio was selected to be 0.40 . Table 1 presents the main input parameters for the VCCTL modelling of cement curing $[1,2]$.

Table 1. Composition of the type CEM I 42.5B Portland cement.

\begin{tabular}{|c|c|c|c|}
\hline Phase & Weight content, wt.\% & Mineral & Weight, g \\
\hline $\mathrm{SiO}_{2}$ & 20.49 & $\mathrm{C}_{3} \mathrm{~S}$ & 61.06 \\
\hline $\mathrm{Al}_{2} \mathrm{O}_{3}$ & 5.06 & $\mathrm{C}_{2} \mathrm{~S}$ & 13.62 \\
\hline $\mathrm{Fe}_{2} \mathrm{O}_{3}$ & 4.14 & $\mathrm{C}_{4} \mathrm{AF}$ & 12.79 \\
\hline $\mathrm{CaO}$ & 62.83 & $\mathrm{C}_{3} \mathrm{~A}$ & 6.50 \\
\hline $\mathrm{MgO}$ & 1.75 & Aqueous solution & 40 \\
\hline $\mathrm{Na}_{2} \mathrm{O}$ & 0.34 & $\mathrm{O}_{2}$ & 0.34 \\
\hline $\mathrm{K}_{2} \mathrm{O}$ & 0.65 & $\mathrm{MgO}$ & 1.78 \\
\hline $\mathrm{SO}_{3}$ & 3.10 & $\mathrm{~K}_{2} \mathrm{O}$ & 0.66 \\
\hline- & - & $\mathrm{Na}_{2} \mathrm{O}$ & 0.34 \\
\hline- & - & $\mathrm{SO}_{3}$ & 3.15 \\
\hline
\end{tabular}

The VCCTL modelling tool constructs a three-dimensional microstructure of the cement paste using the electron microscopical images of plane structures according to which the particle distribution of clinker phases can be reconstructed using the elemental analysis, autocorrelation for neighbouring pixels and the size of platelet structures. Mechanical, physical and transport properties are calculated as functions of the developed microstructures, if the distribution and properties of the initial clinkers, the activation energy and the rate of chemical reactions are known. A combination of hierarchical quantitative variables allows evaluating the long-term performance properties of Portland cements. With certain probabilities, the hydration products occur both on the grain surface exposed to water and in the pore space. The microstructure remains periodic in all the calculations. The kinetics of chemical reactions is affected by the temperature, water alkalinity in pores and its saturation. 


\section{Results and discussion}

Figures 1-3 show the modelling results of Portland cement hydration during 28 days (672 h) within the temperature range of $0-99{ }^{\circ} \mathrm{C}$. Figure 2 presents the results of hydrolysis of clinker phases. During the indicated time period, alite $\left(\mathrm{C}_{3} \mathrm{~A}\right)$ fully dissolves. The most intensive alite dissolution is observed during the first 200 hours, but it does not dissolve completely. The same occurs with belite $\left(\mathrm{C}_{2} \mathrm{~S}\right)$ and alumoferrite $\left(\mathrm{C}_{4} \mathrm{AF}\right)$. With the increasing hydration temperature the clinker hydrolysis intensifies. When contacting with water, the formation of $\mathrm{C}-\mathrm{S}-\mathrm{H}$, portlandite and ettringite (AFt phase) is observed in the initial composition of Portland cement (see Table 1). This is shown in fig. 3.

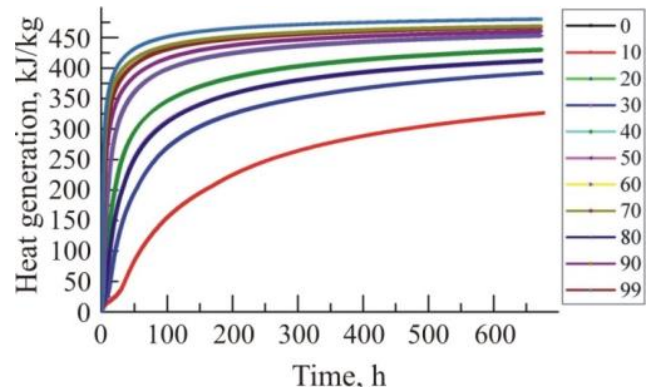

a)

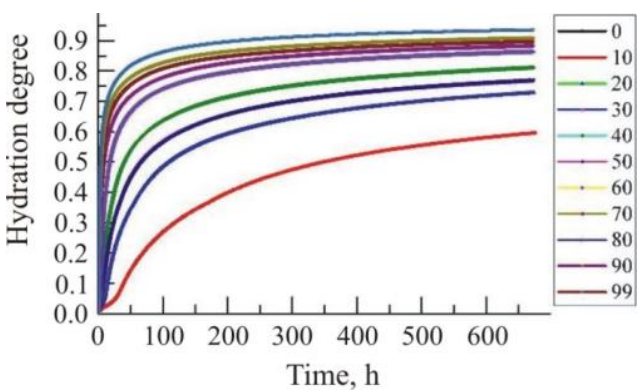

b)

Fig. 1. Time dependences of heat generation (a) and hydration (b).

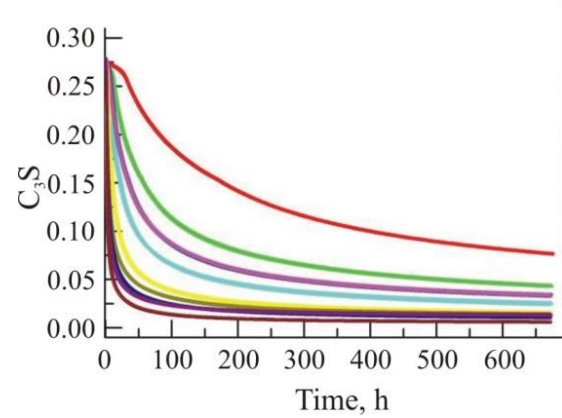

a)

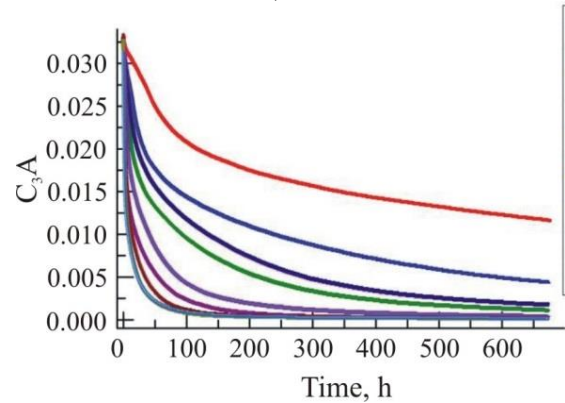

c)
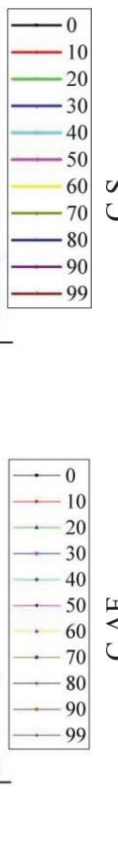

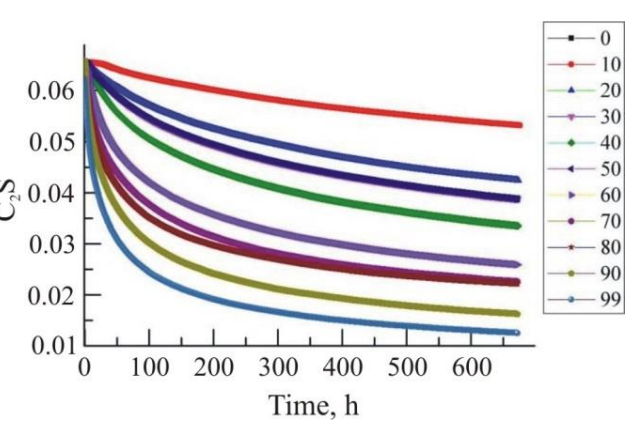

b)

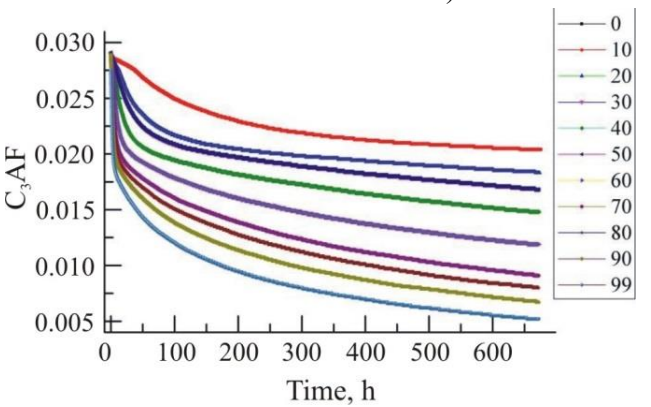

d)

Fig. 2. Time dependencies of clinker phase fractions: $a-$ alite $\left(\mathrm{C}_{3} \mathrm{~S}\right) ; b-$ belite $\left(\mathrm{C}_{2} \mathrm{~S}\right) ; c-$ aluminate $\left(\mathrm{C}_{3} \mathrm{~A}\right) ; d$ - alumoferrite $\left(\mathrm{C}_{4} \mathrm{AF}\right)$ at $0-99^{\circ} \mathrm{C}$. 


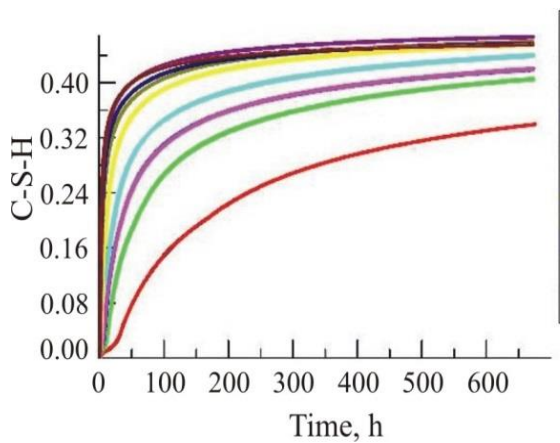

a)

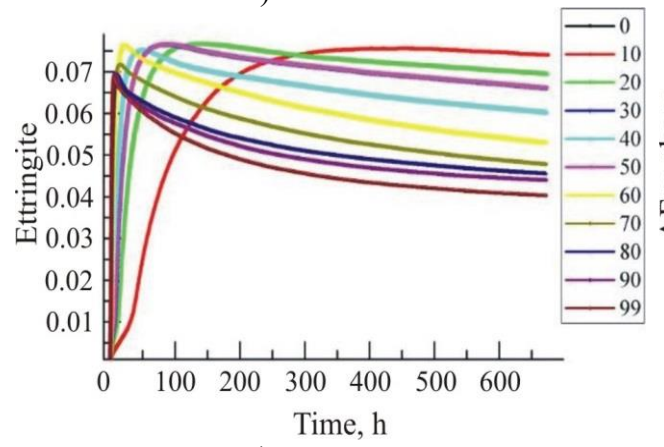

c)

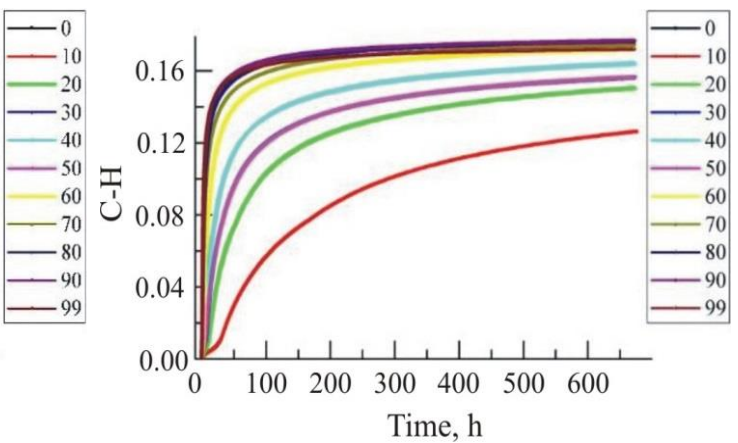

b)

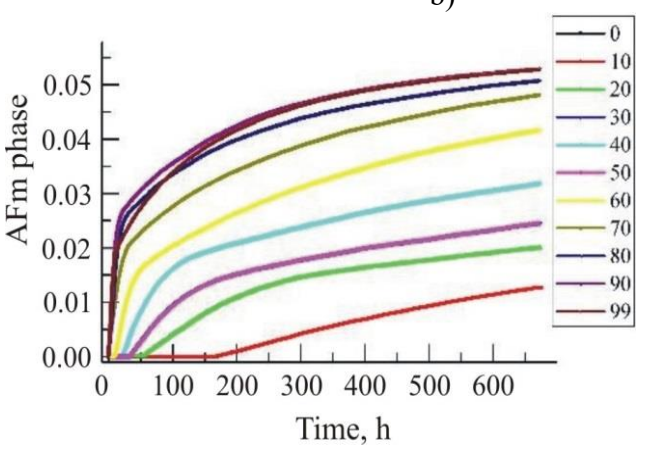

d)
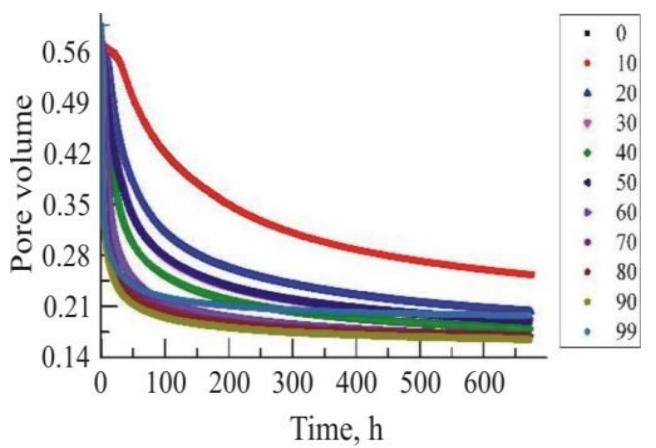

e)

Fig. 3. Time dependencies of hydration products and pore volume: $a-\mathrm{C}-\mathrm{S}-\mathrm{H} ; b-$ portlandite; $c-$ ettringite, $d$-monosulfate (AFm phase); $e$-pore volume.

These figures illustrate the complex processes in Portland cement during its curing. The hydration rate (fig. 1b) is the highest during the first 50 hours and then monotonely decreases. After 672 hours the part of hydration products achieves 0.8 of the solid phase. With the temperature increase, the rate of hydration, heat generation and formation of hydration products substantially enhances. The highest values are observed during the first 50 hours of curing. The rate of hydration correlates with the heat generation (fig. 1a) and the pore volume (fig. 3e), the latter being significantly decreased during the first $160-120$ hours. This is especially prominent at high temperatures. In fig. 4, we show the temperature dependences of the effective elastic moduli, namely the bulk modulus, the shear modulus and Young's modulus. 


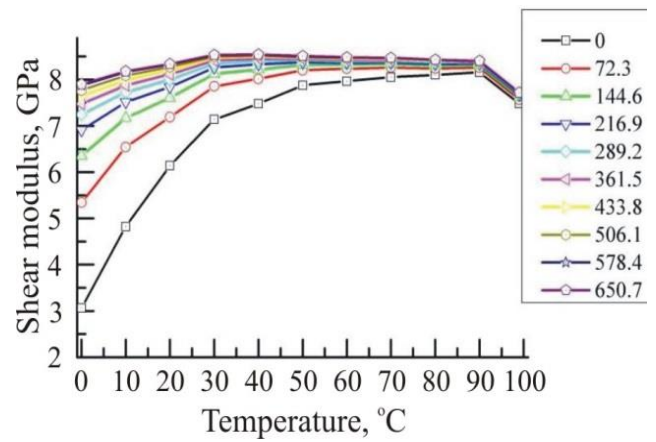

a)

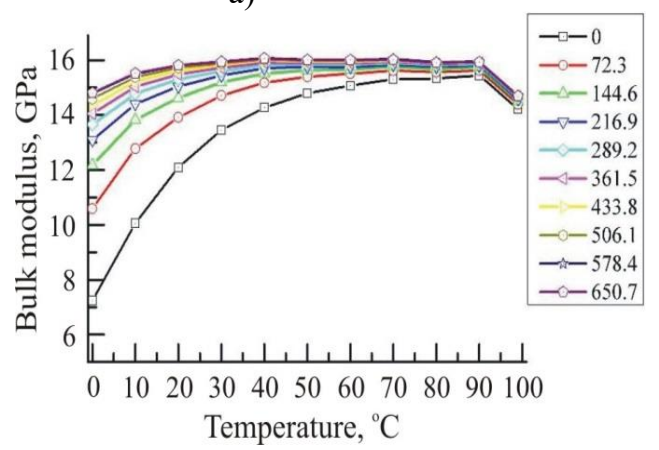

c)

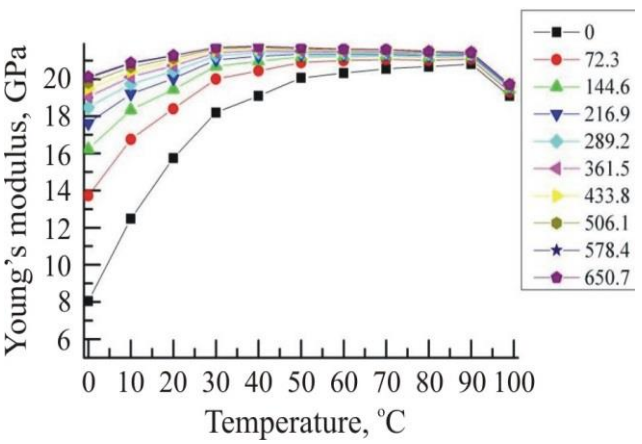

b)

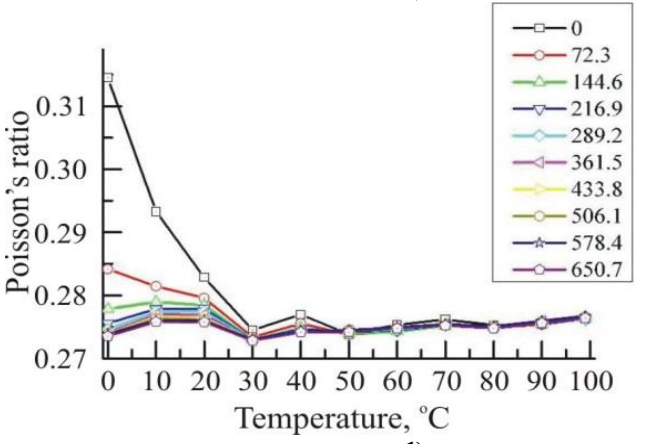

d)

Fig. 4. Temperature dependencies during 0-672 h: a - shear modulus; $b$ - Young's modulus; $\mathrm{c}-$ bulk modulus; $\mathrm{d}$ - Poisson's ratio.

According to fig. 4, the highest values of the effective moduli are observed during the first 500 hours of curing, and their respective curves then gradually reach a plateau. The temperature increase substantially affects the effective moduli at the initial stage, until it achieves $\sim 50{ }^{\circ} \mathrm{C}$. It is found that during the cement hardening, the observed chemical reactions provide the formation of various products. The initial composition of clinker minerals produces a noticeable effect on the quantitative content of the final hydration products. At the initial stage $(24 \mathrm{~h})$, about $50 \%$ of Portland cement transform to hydrates, and after 28 days this figure reaches $\sim 80 \%$. The hydration reactions of alite $\left(\mathrm{C}_{3} \mathrm{~S}\right)$, belite $\left(\mathrm{C}_{2} \mathrm{~S}\right)$, aluminate $\left(\mathrm{C}_{3} \mathrm{~A}\right)$ and alumoferrite $\left(\mathrm{C}_{4} \mathrm{AF}\right)$ are connected by hydrolysis of clinker minerals and the different rate of formation of hydration products. The formation of calcium silicate hydrates of variable composition occurs [1-6]. The hydration rate is determined by $\mathrm{C}_{3} \mathrm{~S}$ hydrolysis which is accompanied by the heat generation and $\mathrm{Ca}(\mathrm{OH})_{2}$ crystallization in the pore space. $\mathrm{Ca}(\mathrm{OH})_{2}$ crystals grow either separately or are absorbed by growing calcium silicate hydrates. Belite $\left(\beta-\mathrm{C}_{2} \mathrm{~S}\right)$ hydration in aqueous solution results in the formation of the same products as in the case with alite. However, in general, the belite dissolution is much slower than that of alite.

The equivalence of the VCCTL modelling of Portland cement curing was examined in works [7-11]. The authors recalculated and evaluated the effective moduli, compared them with statistical data and elastic moduli obtained by the ultrasonic methods. A good agreement was shown between the modelling results and the experimental data on the mechanical properties of cement during its curing for 2-3 days. If the curing time was less than that period, the difference could be $10 \%$. A good correlation in the form of polynomials of $\sim 2.5-3$ degrees was observed between the cement strength and the elastic modulus. 
Of certain interest is agreement between the experimental data and VCCTL modelling of the cement strength properties. We compare the values of the yield stress [12] obtained at $20,40,50$ and $70{ }^{\circ} \mathrm{C}$, depending on the curing time and predicted values of Young's modulus at a 0.4 water-cement ratio.

The deformation of $2 \times 2 \times 2 \mathrm{~cm}$ specimens was performed on a test machine INSTRON at a $0.5 \mathrm{~mm} / \mathrm{min}$ loading rate. The experimental values of the yield stress were approximated using cubic polynomials (fig. 5). Table 2 summarizes the approximation parameters and determination factors.

Table 2. Parameters of cubic polynomial approximation.

\begin{tabular}{|c|c|c|c|c|c|}
\hline \multirow{2}{*}{$\mathbf{T},{ }^{\circ} \mathrm{C}$} & \multicolumn{4}{|c|}{ Parameters } & \multirow{2}{*}{$\begin{array}{l}\text { Determination } \\
\text { factor }\end{array}$} \\
\hline & ${ }^{\mathrm{a}} a_{0}$ & $a_{1}$ & $a_{2}$ & $a_{3}$ & \\
\hline 20 & -4035.7725 & 633.2368 & -33.21594 & 0.59033 & 0.977 \\
\hline 40 & -215796.35335 & 32295.69888 & -1611.31065 & 26.80448 & 0.975 \\
\hline 50 & $-1.3263 \times 10^{6}$ & 193898.0207 & -9449.74502 & 153.5290 & 0.922 \\
\hline 70 & $-1.20731 \times 10^{7}$ & $1.73795 \times 10^{6}$ & -83394.7767 & 1333.9097 & 0.946 \\
\hline
\end{tabular}

According to fig. 5, the yield stress correlates with Young's modulus with a high degree of reliability. With the increasing curing time, the yield stress grows by an order of magnitude at 20,40,50 and $70{ }^{\circ} \mathrm{C}$. The polynomial approximation allows us to conclude that with the temperature growth the yield stress rapidly increases (see Table 2, parameter $a_{1}$ ).

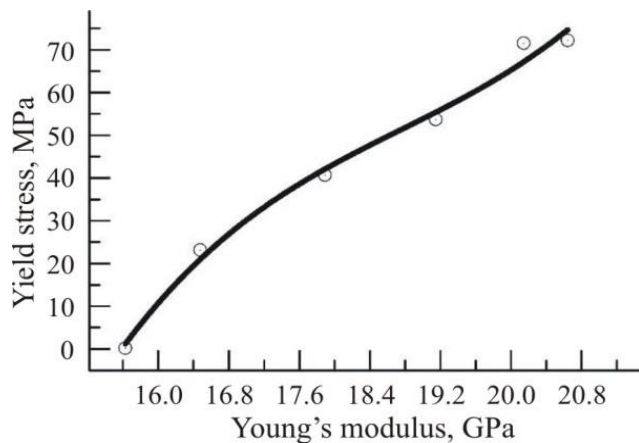

a)

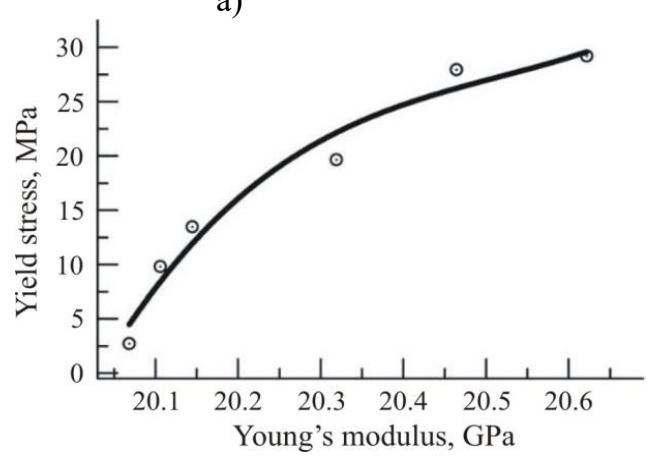

c)

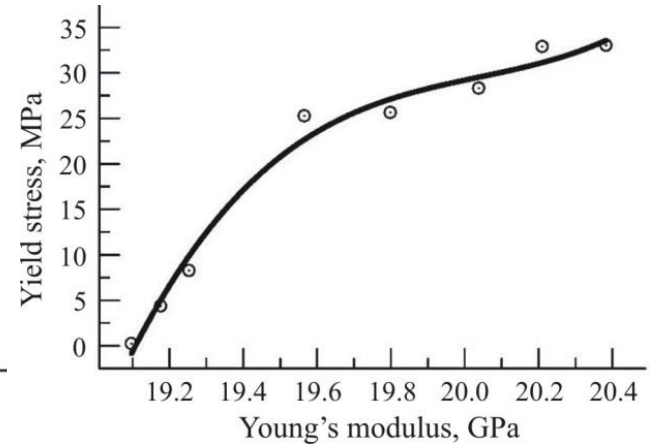

b)

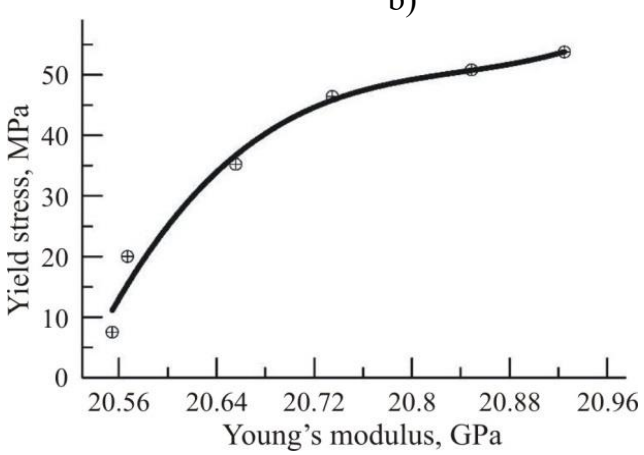

d)

Fig. 5. Approximation of the yield stress and Young's modulus dependence at different temperatures: $a-20^{\circ} \mathrm{C} ; b-40^{\circ} \mathrm{C} ; c-50{ }^{\circ} \mathrm{C} ; d-70{ }^{\circ} \mathrm{C}$. 


\section{Conclusions}

Using the VCCTL tool, we predicted the properties of the type CEM I 42.5B Portland cement during 28-day curing and showed its dependence on the heat generation, quantitative content of clinker phases and hydrates and the pore volume in the cement structure. The hydration degree of CEM I $42.5 \mathrm{~B}$ was $\sim 0.75$ within 28 -day curing. The hydration rate monotonely decreased, and the respective curves then gradually reached a plateau. It was found that aluminate fully dissolved during the indicated time period, while alite dissolved during the first 200 hours. The VCCTL modelling tool allowed us to determine the quantitative content of the main hydration products, such as $\mathrm{C}-\mathrm{S}-\mathrm{H}$ and $\mathrm{CH}$, whose total amount substantially grew during 672 hours. The strength properties of Portland cement were mostly determined by C-S-H and $\mathrm{CH}$. The effective elastic moduli profoundly increased during the first 400 hours. After this time period, the respective curves reached a plateau, and the elastic moduli acquired the values of 16.79, 8.90 and 22.69 MPa, respectively for the bulk, shear and Young's moduli. The equivalence of the VCCTL modelling of Portland cement curing was proved by the exponential function of the yield stress and Young's modulus with a high degree of reliability. It can be assumed that the strength gain of Portland cement was determined by the growth in the crystallinity of C$\mathrm{S}-\mathrm{H}$ and $\mathrm{CH}$.

Authors wish to acknowledge the financial support from the Russian Foundation for Basic Research (Grant N 18-08-01025).

\section{References}

1. Concrete materials monograph, http://ciks.cbt.nist.gov/monograph

2. D. P. Bentz, A Three-dimensional cement hydration and microstructures program, Pt I Hydratation Rate, Heat of Hydration and Chemical Shrinkage, Report NISTIR 5756, 1-47 (Gaithersburg, U.S. Department of Commerce, 1995)

3. D. P. Bentz, P. V. Coveney, E. J. Garboczi, M. F. Kleyn, P. E. Stutzman, Modelling Simul. Mater. Sci. Eng. 2, 783-808 (1994)

4. D. P. Bentz, CEMHYD3D: A Three-dimensional cement hydration and microstructure development modelling package version 3.0, Report NISTIR 6485 (U.S. Department of Commerce, 2000)

5. D. P. Bentz, C. J. Haecker, X. P. Feng, P. E. Stutzman, Proc. 5th Int. VDZ Cong. on Process Technology of Cement Manufacturing, 53-63 (Düsseldorf, Germany, 2003)

6. H. F. W. Taylor, Cement chemistry (Moscow, Mir, 1996)

7. S. T. Erdogan, E. J. Garboczi, J. W. Bullard, Proc. Int. Conf. on Durability of Building Materials and Components, 1-8 (Istanbul - Turkey, 2008)

8. E. J. Garboczi, J. G. Berryman, Mech. Mater. 33, 455-470 (2001)

9. Z. Sun, E. J. Garboczi, S. P. Shah, Cement Concrete Comp. 29, 22-38 (2007)

10. C.-J. Haecker, E .J. Garboczi, J. W. Bullard, R. B. Bohn, Z. Sun, S. P. Shah, T. Voigt, Cement Concrete Comp. 35,1948-1960 (2005)

11. L. Valentini, M. Parisatto, V. Russo, G. Ferrari, J. W. Bullard, R. J. Angel, M. C. Dalconi, G. Artioli, Cement Concrete Comp. 52, 54-63 (2014)

12. A. I. Gnyrya, Yu. A. Abzaev, S. V. Korobkov, K. S. Gauss, IOP Conf. Series: EES, 193 012010 doi: 10.1088/1755-1315/193/1/012010 (2018). 